\title{
Contrasting reservoirs for Schistosoma japonicum between marshland and hilly regions in Anhui, China - a two-year longitudinal parasitological survey
}

\author{
DA-BING LU ${ }^{1 *}$, TIAN-PING WANG ${ }^{2}$, JAMES W. RUDGE ${ }^{1}$, CHRISTL A. DONNELLY ${ }^{1}$, \\ GUO-REN FANG ${ }^{2}$ and JOANNE P. WEBSTER ${ }^{1}$ \\ ${ }^{1}$ Department of Infectious Disease Epidemiology, Faculty of Medicine, Imperial College, Norfolk Place, London W2 1PG, UK \\ ${ }^{2}$ Anhui Institute of Parasitic Diseases, Wuhu, People's Republic of China
}

(Received 5 March 2009; revised 5 May, 11 fune and 30 Fune 2009; accepted 10 fuly 2009; first published online 2 September 2009)

\section{SUMMARY}

Schistosoma japonicum remains highly endemic in many counties in China and has recently re-emerged, to a large extent, in previously controlled areas. To test the hypothesis that small rodents and less agriculturally important domestic animals such as dogs and cats may play an important role in the transmission and potential re-emergence of this disease, an annual investigation of $S$. japonicum among humans, domestic animals and rodents, combined with detailed surveys of the snail intermediate host, was performed across 3 marshland villages and 3 hilly villages in Anhui province of China over 2 consecutive years. The highest infection prevalence and intensity observed across all mammals was in rodents in the hilly region; while in the marshland, bovines were suspected as the main reservoirs. However, relatively high infection prevalence levels were also found in dogs and cats in both regions. Such results may have implications for the current human- and bovine-oriented control policy for this medically and veterinarily important disease, particularly within the hilly regions of mainland China.

Key words: Schistosoma japonicum, schistosomiasis, rodents, domestic animals, infection prevalence, China.

\section{INTRODUCTION}

Schistosomiasis is one of the world's great neglected diseases, caused by blood flukes of the genus Schistosoma. Of the 3 major schistosome species infecting humans, Schistosoma japonicum presents one of the greatest challenges to control due, at least in part, to its zoonotic nature. Although great progress has been made in China over the past 5 decades where, for example, the estimated number of infected people was reduced from 11.6 million in $1950 \mathrm{~s}$ to 0.7 million in 2000 , the disease remains endemic in 110 counties, most belonging to the lake/marshland areas, within seven provinces in China (Zhou et al. 2005), with an estimate of up to $56 \%$ infection in some villages (Wang et al. 2006a). Moreover, particularly since the mid-1990s, S. japonicum has reemerged in previously controlled areas and further snail-infested areas have been found in formerly nonendemic provinces such as Shanghai, Zhejiang and Fujian (Zhou et al. 2004). Such worrying trends in the re-emergence and/or the continued presence of

* Corresponding author: Department of Infectious Disease Epidemiology, Faculty of Medicine, Imperial College (St Mary's Campus), Norfolk Place, London W2 1PG, UK. Tel: +0207594 3819. Fax: +020 74023927. E-mail: dabing.lu@imperial.ac.uk high infection levels in certain areas may suggest some ongoing factors in the disease transmission which have been long neglected.

Based upon previous estimates of their relative transmission index (an index of the role each species may play in $S$. japonicum transmission based on the size of each species population, their infection prevalence, excreted faeces per day, and eggs per gram of faeces), bovines are generally considered as the most important species in terms of chemotherapy-based policy (Ross et al. 2001; Wang et al. 2005; Gray et al. 2007). Thus, most effort has been invested in either the development of a potential vaccine against $S$. japonicum in bovines (McManus and Bartley, 2004; Wu et al. 2005), the chemotherapeutic treatment of bovines (Gray et al. 2007), and/or the elimination and replacement of bovines (and goats) with machines (Chen et al. 2004; Wang et al. 2009), together with the fencing of pigs. Prevention or control measures for other agriculturally 'less important' domestic animals, such as dogs or cats, are not mentioned within the newly passed 'The Regulation of Schistosomiasis Control (2006)', nor indeed were even included during the 3 previous nation-wide surveys conducted in 1989, 1995 and 2004, respectively (Li et al. 2005; Balen et al. 2007) or annual monitoring surveillance across the whole endemic areas (Zhao et al. 2005). Likewise, the potential 
importance of wild animals, in particular that of small rodents, in the transmission or re-emergence of S. japonicum has also long been neglected (Yao et al. 1989; Zheng, 2006). Although previous studies have occasionally reported high infection prevalence levels in rodents of up to, for example, $64 \%$ in one area of Yunnan in China (Cheng and Gong, 1989), $59.8 \%$ in 2 islets along the Yangtze river in China (Xu et al. 1999), and up to $95.5 \%$ in Leyte, the Philippines (Fedorko, 1999), their subsequent role in the transmission of schistosomiasis has generally been dismissed. Reasons for this may relate to the relatively low amount of excreted faeces from rodents, between 1 and $2 \mathrm{~g}$ of faeces for a host per day (Ebihara $e t$ al. 1998), a potentially low egg viability as reported by some studies (Ho, 1963 ; Mitchell et al. 1990), and/or a potential 'natural resistance' in Microtus fortis, one common species of lake rodents in Hunan province of China, against this parasite (He et al. 1999a,b). However, given contrasting reports that, for example, many viable eggs are excreted in the faeces from Rattus norvegicus infected with $S$. japonicum (Wu, 1957 ) and miracidia per gram of faeces from infected rodents can be 14.5 times higher than that obtained from the equivalent human samples (Mao, 1990), such a general omission and/or dismissal of the potential role of rodents in the transmission of S. japonicum may be surprising. Furthermore, recent molecular research in Anhui Province of China, using polymorphic $S$. japonicum microsatellite markers (Shrivastava et al. 2003; Wang et al. 2006 b), revealed that a large proportion of alleles observed from cercariae samples from snails were not observed in any miracidia from the human or domestic animals sampled in the same areas, thereby indicating that additional potential definitive host reservoir species may play a role in the ongoing transmission of this important disease.

Such obvious contrasting views and gaps in our current understanding of this multi-host pathogen leads us to question what may be the actual infection profile of S. japonicum in dogs, cats and rodents within mainland China and, moreover, whether such species could maintain transmission of the disease even if infections within bovines, goats and/or pigs can be successfully controlled or eliminated through current targeted treatment programmes. Therefore, throughout 2006-2007, parasitological surveys of the infected snail distribution prior to transmission seasons and of the prevalence and infection intensity in all species of definite hosts present after transmission were performed across 2 contrasting geographical regions within Anhui province of China: in the marshland where the disease persists, and in the hilly region where the disease was previously controlled, in order to evaluate the potential role of less agriculturally important domestic animals (dogs or cats) and wildlife (small rodents) in the transmission of the disease.
MATERIALS AND METHODS

\section{Site locations}

Research sites were set in Tongling County and in Shitai County, Anhui Province of China. Tongling County is located on the south bank of the Yangtze River, classified as marshland region with schistosomiasis persistence. According to the local historical recording (provided by Tongling Schistosomiasis Control Station), at the end of 2004, a total of 126 villages within 9 townships were endemic for the disease, with around 204900 residents at risk of infection; the infected snail area was $7144300 \mathrm{~m}^{2}$, found on 34 habitats within 6 townships of 21 villages; the snail density on average was 0.37 per $0 \cdot 11 \mathrm{~m}^{2}$ (frame), and infected snail density was $0 \cdot 001$ per $0.11 \mathrm{~m}^{2}$; the mean prevalence in humans was $3 \cdot 3 \%$, with the highest up to $7 \cdot 1 \%$ in some villages; the infection prevalence level among cattle and water buffalo was $8 \cdot 5 \%$ on average across the county, with the highest $30 \cdot 8 \%$ in some villages; acute cases have annually occurred over recent years.

Shitai County, a hilly region in which the disease has re-emerged since 1995, lies in the southern Anhui. According to local historical recordings (provided by Shitai County Centre for Disease Control), in 1985 disease control reached 'transmission control' level at the scale of county, with the prevalence in humans and in cattle both less than $1 \%$, and no new infections in children under 12 years old nor any acute cases recorded. However, since 1995 the infected snail habitats have increased every year. During 2001-2005, the prevalence at the countylevel in bovines fluctuated between 0 and $1.7 \%$ and in humans between $0 \cdot 2$ and $1 \cdot 0 \%$ (provided by Shitai County Centre for Disease Control), and in 2003, an outbreak of acute schistosomiasis occurred in one village (Cao and $\mathrm{Wu}, 2004$ ).

Based on the river systems, the distance from the county centre, and the availability of accurate survey data recordings (annual reports to the Provincial Disease Control Station) from the previous 3 years, 3 villages in Tongling county, namely Guanghui, Heping, and Xingzhuang from Laozhou Township located on an island in the middle of the Yangtze River, were chosen for the current investigation. Meanwhile, in Shitai county 3 villages: Longquan from Dingxiang Township, Longshang from Chili Township and Yuantou from Ketian Township, were chosen. Table 1 shows general information on demography, schistosomiasis endemic status, and control measures in the 6 villages in 2005 and Fig. 1 displays their geographical locations.

\section{Snail surveys}

Systematic surveys of snails were carried out in all suspected snail habitats across the 6 villages during March to April of 2006 and of 2007. According to the 
Table 1. General information in the sampled villages in 2005

\begin{tabular}{|c|c|c|c|c|c|c|}
\hline \multirow[b]{2}{*}{ Variables } & \multicolumn{3}{|c|}{ Marshland villages } & \multicolumn{3}{|l|}{ Hilly villages } \\
\hline & Guanghui & Heping & Xingzhuang & Longquan & Longshang & Yuantou \\
\hline \multicolumn{7}{|l|}{ Coordinates } \\
\hline Latitude & $30^{\circ} 56 \cdot 96^{\prime}$ & $30^{\circ} 59 \cdot 15^{\prime}$ & $30^{\circ} 58 \cdot 54^{\prime}$ & $30^{\circ} 18 \cdot 66^{\prime}$ & $30^{\circ} 21 \cdot 83^{\prime}$ & $30^{\circ} 04 \cdot 95^{\prime}$ \\
\hline Longitude & $117^{\circ} 44 \cdot 87^{\prime}$ & $117^{\circ} 44^{\cdot} 96^{\prime}$ & $117^{\circ} 45 \cdot 25^{\prime}$ & $117^{\circ} 31 \cdot 64^{\prime}$ & $117^{\circ} 50 \cdot 40^{\prime}$ & $117^{\circ} 30 \cdot 24^{\prime}$ \\
\hline $\begin{array}{l}\text { Registered } \\
\text { population }\end{array}$ & 2686 & 1758 & 2039 & 1137 & 866 & 759 \\
\hline Houses & 713 & 450 & 560 & 282 & 245 & 209 \\
\hline $\begin{array}{l}\text { With piped water } \\
\text { or water from well }\end{array}$ & $100 \%$ & $100 \%$ & $100 \%$ & $40 \cdot 43 \%$ & $76 \cdot 33 \%$ & $52 \cdot 15 \%$ \\
\hline $\begin{array}{l}\text { With a bio-gas toilet } \\
\text { (in hilly region) or } \\
\text { parasite-free toilet } \\
\text { (in marshland) }\end{array}$ & $44 \cdot 88 \%$ & $37 \cdot 78 \%$ & $35 \cdot 71 \%$ & $39 \cdot 01 \%$ & $11 \cdot 84 \%$ & $47 \cdot 85 \%$ \\
\hline \multicolumn{7}{|l|}{$\begin{array}{l}\text { Schistosomiasis } \\
\text { endemic status }\end{array}$} \\
\hline Snail habitats & 2 & 2 & 1 & 29 & 35 & 34 \\
\hline $\begin{array}{l}\text { Infected snail } \\
\text { habitats }\end{array}$ & 1 & 2 & 1 & 4 & 6 & 5 \\
\hline $\begin{array}{l}\text { Infected snail } \\
\text { density }\left(/ 0 \cdot 11 \mathrm{~m}^{2}\right)\end{array}$ & $0 \cdot 004(7 / 1741)$ & $0 \cdot 0018(2 / 1115)$ & $0 \cdot 0423(13 / 307)$ & $0 \cdot 0030(14 / 4658)$ & $0 \cdot 012(11 / 920)$ & $0 \cdot 0154(32 / 2072)$ \\
\hline $\begin{array}{l}\text { Infected snail } \\
\text { prevalence }(\%)\end{array}$ & $1 \cdot 23(7 / 569)$ & $0 \cdot 17(2 / 1180)$ & $5 \cdot 31(13 / 245)$ & $0 \cdot 06(14 / 23802)$ & $0 \cdot 51(11 / 2172)$ & $0 \cdot 14(32 / 22116)$ \\
\hline $\begin{array}{l}\text { Number of acute } \\
\text { schistosomiases }\end{array}$ & 2 & 1 & 0 & 0 & 0 & 0 \\
\hline $\begin{array}{l}\text { Expected prevalence } \\
\text { in humans } \\
\text { Control measures }\end{array}$ & $\geqslant 10 \%$ & $5-10 \%$ & $5-10 \%$ & $5-10 \%$ & $5-10 \%$ & $5-10 \%$ \\
\hline \multicolumn{7}{|l|}{ Mollusciciding } \\
\hline $\begin{array}{l}\text { Infected snail } \\
\text { habitats }\end{array}$ & 2 times & 1 time & 1 time & 4 times & 3 times & $3-4$ times \\
\hline $\begin{array}{l}\text { Non-infected } \\
\text { snail habitats }\end{array}$ & 0 & 0 & 0 & $1-3$ times & 1-3 times & $2-3$ times \\
\hline $\begin{array}{l}\text { Selective treatment } \\
\text { in humans }\end{array}$ & Yes & Yes & $\begin{array}{l}\text { No, but } \\
\text { in } 2004\end{array}$ & Yes & $\begin{array}{l}\text { No, but } \\
\text { in } 2004\end{array}$ & $\begin{array}{l}\text { No, but } \\
\text { in } 2004\end{array}$ \\
\hline $\begin{array}{l}\text { Health education } \\
\text { in humans }\end{array}$ & Yes & Yes & Yes & Yes & Yes & Yes \\
\hline
\end{tabular}

standard procedure (Anonymous, 1990), frames, each $0 \cdot 11 \mathrm{~m}^{2}$, were set at regularly-spaced locations within snail habitats, and all $O$. hupensis snails found within each frame were collected in order to measure the density of snails and of infected snails. In the hilly region, where snail habitats are known to be concentrated within irrigation ditches, frames were placed at regular distances $(5 \mathrm{~m}$ or $10 \mathrm{~m}$ ) along these ditches. In the marshland region, where snails are more widely dispersed across marshy areas of land, frames were set in an equally-spaced lattice formation $(20 \mathrm{~m} \times 20 \mathrm{~m})$. The captured snails from the field were checked in the laboratory the following day for death and then for infection by using a crushing method (Anonymous, 1990). The numbers of snails or infected snails were recorded by frames and habitats.

\section{Schistosomiasis prevalence and intensity epidemiological survey}

All the humans and domestic animals from each village were regarded as subjects of this survey, and
1 faecal sample per host was collected each time during September-October 2006 and of 2007. Stool examinations were conducted using the miracidia hatching test (Anonymous, 1990; Yu et al. 2007) to diagnose $S$. japonicum infection for all species of definitive hosts. For humans, only those antibodypositive during an annual indirect haemagglutination assay (Gui et al. 1991) were asked to provide faecal material, which, if positive in egg hatching, was subjected to a further Kato-Katz test with 3 slides thicksmeared per sample to quantify the intensity of infection with the index of eggs per gram faeces (Feldmeier and Poggensee, 1993).

A veterinarian was hired to obtain faeces from cattle, water buffalo, goats and dogs by direct rectal sampling wherever possible. Faecal samples from cats were obtained through scrutinizing the neighbouring ground of the house to which a cat belonged. Only a subsample of pigs were given stool examinations, as pigs tend to be always fenced due to their value in meat and/or behaviour in terms of destroying crops when free-roaming, and therefore have few 


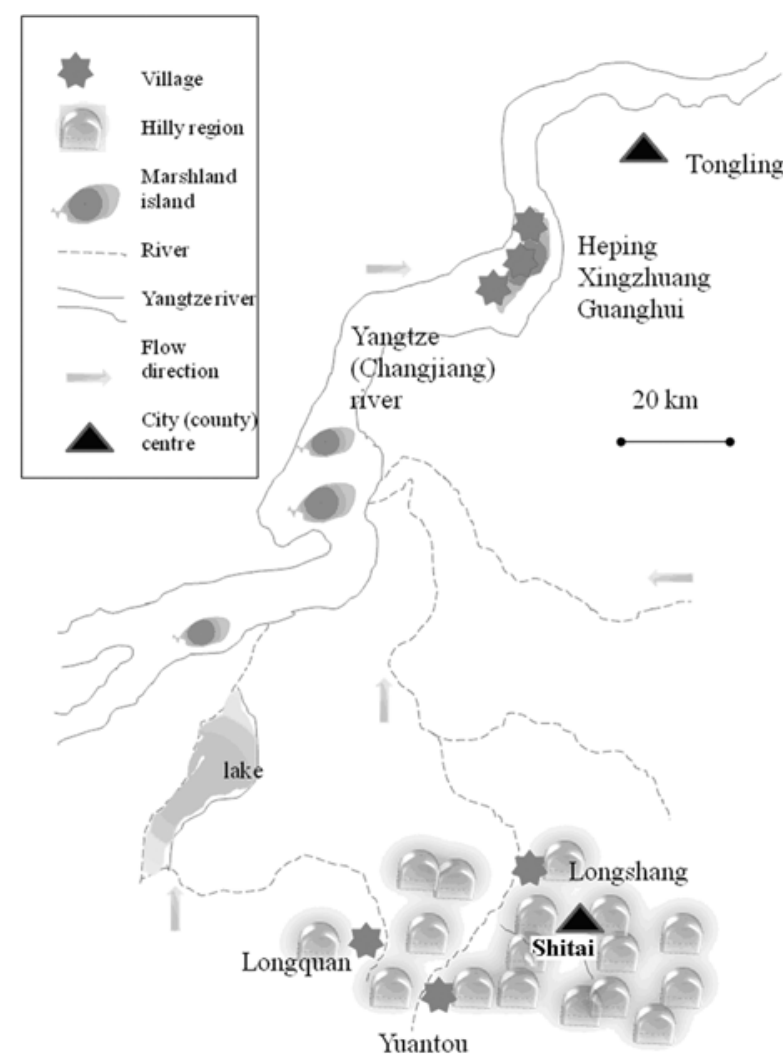

Fig. 1. Map showing the 3 marshland and 3 hilly villages in Anhui, China.

opportunities for water contact. Small rodents were captured by setting live traps in the late afternoon and checking at dawn for 3 consecutive days and captured rodents were kept inside overnight for obtaining their faecal samples. For domestic animals and small rodents, infection intensity data were calculated as miracidia plus eggs (from sediments after hatched) per gram (EPG) (Anonymous, 1990).

The number of discharged eggs per host per day for each species was calculated by the arithmetic mean EPG (of infected individuals) times the amount of faeces excreted per day per host for that species. This was then used in calculation of the contamination index (the total number of discharged eggs per day) for each species, with the exception of rodents due to the inherent difficulties in accurately estimating the population sizes of wild rodents (Calhoun, 1962; Meehan, 1984), using the formula: contamination index $=$ the number of discharged eggs per host per day $\times$ the number of the total host individuals $\times$ infection prevalence (Wang et al. 2005; Gray et al. 2007).

Throughout the 2 years of investigation in the sampled villages, control measures were implemented as usual by local health staff. These involved selective chemotherapy of humans, with praziquantel at a dose of $40 \mathrm{mg} / \mathrm{kg}$ body weight (Chen, 2005) based on the indirect hemagglutination assay (Zhu, 2005), health education and mollusciciding with niclosamide, a current chemical widely used in China (Yuan et al. 2005). Due to the increasing concern, from both officials and health workers, over the high prevalence of schistosomiasis in bovines and goats in the marshland revealed in 2006 , with special funding from the local government, all bovines and goats raised in the marshy villages have been eliminated since January 2007.

\section{Statistical methods}

Snail density and infected snail density were measured as the number of snails per $0 \cdot 11 \mathrm{~m}^{2}$ at levels of villages (Anonymous, 1990). A significant difference in infection prevalence in snails between years was tested with Chi-square test. Due to low examination rates and small sample sizes of definitive hosts in each village (See Table 2 and Table 4), infection prevalence in definitive hosts was measured at the level of region and the significant difference among species was shown by their $95 \%$ confidence intervals. Infection intensity in animals was calculated as the arithmetic mean or the geometric mean of miracidia plus eggs per gram of faeces of infected individuals. The significant difference in infection intensity among species was tested with the non-parametric Kruskal-Wallis test using SPSS 11.0 software (SPSS Base 11.0 for Windows. SPSS Inc. Chicago, Illinois, 2002).

\section{Ethical considerations}

Ethical clearance for the study was obtained from the Scientific Committee, Anhui Institute of Parasitic Diseases. A blood test for antibodies to $S$. japonicum in all residents at home, conducted by local health workers, is an annual routine task required from the local health department, for selecting targeted individuals for treatment. Oral informed consent was obtained from all adults and from parents or guardians of minors who were involved in the project, and from owners whose domestic animals were sampled. Owners and local village leaders were informed of the infected dogs or cats and control advice was given. Captured rodents were humanely euthanized with ether in black bags if positive for $S$. japonicum in stool examination; otherwise, they were released at their original point of capture the following day.

\section{RESULTS}

\section{Infection prevalence in intermediate host snails}

Infected snails were identified in all the sampled villages across both years (Table 3 ). In the marshland, both the infected snail density and the proportion of infected snails was lower in 2007 relative to the numbers in 2006, with a significant difference in prevalence seen in Heping $\left(\mathrm{X}^{2}=7 \cdot 97\right.$, D.F. $=1$, $P<0 \cdot 01)$. In contrast, in the hilly villages, with the 
Table 2. Censored population sizes of each species of definitive hosts in the two regions in 2006 and in 2007

\begin{tabular}{|c|c|c|c|c|c|c|c|c|c|}
\hline \multirow[b]{2}{*}{ Hosts } & \multirow[b]{2}{*}{ Years } & \multicolumn{4}{|c|}{ Marshland villages } & \multicolumn{4}{|c|}{ Hilly villages } \\
\hline & & Guanghui & Heping & Xingzhuang & Total & Longquan & Longshang & Yuantou & Total \\
\hline \multirow[t]{2}{*}{ Humans $^{\mathrm{a}}$} & 2006 & $325(1213)$ & $107(866)$ & $91(984)$ & $523(3063)$ & $107(553)$ & $76(493)$ & $62(343)$ & $245(1389)$ \\
\hline & 2007 & $125(1244)$ & $39(910)$ & $24(895)$ & $188(3049)$ & $52(601)$ & $61(507)$ & $37(311)$ & $150(1419)$ \\
\hline \multirow[t]{2}{*}{ Cattle } & 2006 & 281 & 22 & 45 & 348 & 1 & 7 & - & 8 \\
\hline & 2007 & - & - & - & & 1 & 6 & - & 7 \\
\hline \multirow[t]{2}{*}{ Buffalo } & 2006 & 36 & 11 & 13 & 60 & - & - & - & \\
\hline & 2007 & - & - & - & & - & - & - & \\
\hline \multirow[t]{2}{*}{ Pigs } & 2006 & 37 & 34 & 48 & 119 & 303 & 257 & 212 & 772 \\
\hline & 2007 & 31 & 27 & 35 & 93 & 284 & 329 & 241 & 854 \\
\hline \multirow[t]{2}{*}{ Goats } & 2006 & - & - & 21 & 21 & - & - & - & \\
\hline & 2007 & & & & & & & & \\
\hline \multirow[t]{2}{*}{ Dogs } & 2006 & 20 & 18 & 36 & 74 & 43 & 29 & 17 & 89 \\
\hline & 2007 & 32 & 35 & 34 & 101 & 36 & 48 & 26 & 110 \\
\hline \multirow[t]{2}{*}{ Cats } & 2006 & 30 & 3 & 1 & 34 & 25 & 45 & 43 & 113 \\
\hline & 2007 & 10 & 8 & 4 & 22 & 18 & 49 & 28 & 95 \\
\hline \multirow{2}{*}{ Rodents $^{b}$} & 2006 & (146) & (100) & (88) & (334) & (141) & $(142)$ & (141) & (424) \\
\hline & 2007 & (113) & (112) & (111) & (336) & (106) & (108) & (110) & (324) \\
\hline
\end{tabular}

a Numbers in parentheses refer to people who underwent IHA for detection of $S$. japonicum and numbers without parentheses refer to people positive with the IHA test.

b Numbers in parentheses refer to traps used for small rodents.

Table 3. Snail distribution in the sampled villages in 2006 and 2007

\begin{tabular}{|c|c|c|c|c|c|c|c|}
\hline Villages & Year & $\begin{array}{l}\text { Snail } \\
\text { habitats }\end{array}$ & $\begin{array}{l}\text { Infected } \\
\text { snail } \\
\text { habitats }^{\text {a }}\end{array}$ & $\begin{array}{l}\text { Snail area } \\
\left(\mathrm{m}^{2}\right)\end{array}$ & $\begin{array}{l}\text { Snail } \\
\text { density } \\
\left(/ 0 \cdot 11 \mathrm{~m}^{2}\right)\end{array}$ & $\begin{array}{l}\text { Infected } \\
\text { snail density } \\
\left(/ 0 \cdot 11 \mathrm{~m}^{2}\right)\end{array}$ & $\begin{array}{l}\text { Infection } \\
\text { prevalence } \\
(\%)\end{array}$ \\
\hline Guanghui & $\begin{array}{l}2006 \\
2007\end{array}$ & $\begin{array}{l}2 \\
2\end{array}$ & $\begin{array}{l}1(1) \\
1(1)\end{array}$ & $\begin{array}{l}600200 \\
600200\end{array}$ & $\begin{array}{l}0 \cdot 73 \\
0 \cdot 32\end{array}$ & $\begin{array}{l}0 \cdot 0036(6 / 1667) \\
0 \cdot 0018(3 / 1704)\end{array}$ & $\begin{array}{l}0 \cdot 49(6 / 1222) \\
0 \cdot 55(3 / 544)\end{array}$ \\
\hline Heping & $\begin{array}{l}2006 \\
2007\end{array}$ & $\begin{array}{l}2 \\
2\end{array}$ & $\begin{array}{l}2(2) \\
2(2)\end{array}$ & $\begin{array}{l}275800 \\
399650\end{array}$ & $\begin{array}{l}0 \cdot 75 \\
0 \cdot 67\end{array}$ & $\begin{array}{l}0 \cdot 0166(14 / 843) \\
0 \cdot 0026(3 / 1135)\end{array}$ & $\begin{array}{l}2 \cdot 22(14 / 632) \\
0 \cdot 40(3 / 756)\end{array}$ \\
\hline Xingzhuang & $\begin{array}{l}2006 \\
2007\end{array}$ & $\begin{array}{l}1 \\
1\end{array}$ & $\begin{array}{l}1(1) \\
1(1)\end{array}$ & $\begin{array}{l}100000 \\
123100\end{array}$ & $\begin{array}{l}1 \cdot 10 \\
0 \cdot 92\end{array}$ & $\begin{array}{l}0 \cdot 0062(2 / 322) \\
0 \cdot 0027(1 / 366)\end{array}$ & $\begin{array}{l}0 \cdot 56(2 / 355) \\
0 \cdot 30(1 / 336)\end{array}$ \\
\hline Longquan & $\begin{array}{l}2006 \\
2007\end{array}$ & $\begin{array}{l}30 \\
30\end{array}$ & $\begin{array}{l}5(0) \\
5(1)\end{array}$ & $\begin{array}{l}90754 \\
90754\end{array}$ & $\begin{array}{l}2 \cdot 82 \\
2 \cdot 28\end{array}$ & $\begin{array}{l}0 \cdot 0063(17 / 2722) \\
0 \cdot 0073(16 / 2204)\end{array}$ & $\begin{array}{l}0 \cdot 22(17 / 7683) \\
0 \cdot 32(16 / 5018)\end{array}$ \\
\hline Longshang & $\begin{array}{l}2006 \\
2007\end{array}$ & $\begin{array}{l}35 \\
38\end{array}$ & $\begin{array}{r}3(1) \\
10(1)\end{array}$ & $\begin{array}{l}62612 \\
53676\end{array}$ & $\begin{array}{l}1 \cdot 79 \\
2 \cdot 67\end{array}$ & $\begin{array}{l}0 \cdot 0098(10 / 1020) \\
0 \cdot 0454(56 / 1233)\end{array}$ & $\begin{array}{l}0 \cdot 55(10 / 1823) \\
1 \cdot 70(56 / 3296)\end{array}$ \\
\hline Yuantou & $\begin{array}{l}2006 \\
2007\end{array}$ & $\begin{array}{l}34 \\
34\end{array}$ & $\begin{array}{l}5(1) \\
2(1)\end{array}$ & $\begin{array}{l}83977 \\
83977\end{array}$ & $\begin{array}{l}2 \cdot 48 \\
2 \cdot 23\end{array}$ & $\begin{array}{l}0 \cdot 0178(24 / 1352) \\
0 \cdot 0034(4 / 1174)\end{array}$ & $\begin{array}{l}0 \cdot 72(24 / 3349) \\
0 \cdot 15(4 / 2613)\end{array}$ \\
\hline
\end{tabular}

a Numbers in parentheses indicate the same infected habitats also found in the previous year.

exception of Yuantou, both indices were higher by 2007 , with a noteworthy difference in prevalence found in Longshang $\left(\mathrm{X}^{2}=11 \cdot 32\right.$, D.F. $\left.=1, P<0 \cdot 01\right)$. This apparent increase in prevalence in Longshang was accompanied by an increase in the number of infected snail habitats, with 10 out of 38 snail habitats found with infected snails in 2007, whereas only 3 infected snail habitats were observed in 2006 and 6 in 2005 (Table 1 and Table 3).

\section{Infection prevalence and intensity in definitive hosts}

The infected species, not including humans, in the marshland, in order of infection prevalence, were goats, cattle, water buffalo and dogs, whereas in the hilly region were rodents, dogs and cats in 2006 (Table 4). In 2007 after bovines and goats had been removed from the marshland, the prevalence profile in definitive hosts changed with cats and dogs on the top of the list, while in the hilly region the dogs became the species with the highest infection prevalence among all species, with rodents second (Table 4). However, the prevalence in dogs and cats was not significantly higher in 2007, compared to in 2006, in either region (in marshland, $\mathrm{X}^{2}=0 \cdot 03$, D.F. $=1, P=$ $0 \cdot 86$; in hilly region, D.F. $=1, \mathrm{X}^{2}=0 \cdot 0001, P=1 \cdot 0$ ).

Infected rodents were found in each hilly village in both years, often at high prevalence levels of between 
Table 4. Prevalence and infection intensity in populations of different definitive hosts in 2006 and 2007

\begin{tabular}{|c|c|c|c|c|c|c|c|c|c|c|c|c|c|c|c|}
\hline \multirow[b]{4}{*}{ Hosts } & \multirow[b]{4}{*}{ Year } & \multicolumn{7}{|c|}{ Marshland villages } & \multicolumn{7}{|c|}{ Hilly villages } \\
\hline & & \multirow{2}{*}{\multicolumn{4}{|c|}{ No. infected/No. examined }} & \multirow{3}{*}{$\begin{array}{l}\text { Prevalence } \\
\%(95 \% \text { CI })\end{array}$} & \multicolumn{2}{|c|}{ Infection intensity $(\mathrm{EPG})^{\mathrm{a}}$} & \multirow{2}{*}{\multicolumn{4}{|c|}{ No. infected/No. examined }} & \multirow{3}{*}{$\begin{array}{l}\text { Prevalence } \\
\%(95 \% \text { CI })\end{array}$} & \multicolumn{2}{|c|}{ Infection intensity $(\mathrm{EPG})^{\mathrm{a}}$} \\
\hline & & & & & & & Aritl & Geor & & & & & & Ari & Geol \\
\hline & & $\mathrm{GH}$ & $\mathrm{HP}$ & $\mathrm{xZ}$ & Total & & mean (s.D.) & mean (Range) & LQ & $\mathrm{LS}$ & YT & Total & & mean (S.D.) & mean (Range) \\
\hline \multirow[t]{2}{*}{ Humans $^{b}$} & 2006 & $1 / 325$ & $0 / 107$ & $1 / 88$ & $2 / 520$ & $\begin{array}{l}0 \cdot 4 \\
(0 \cdot 0-1 \cdot 4)\end{array}$ & $\begin{array}{c}\text { No eggs by } \\
\text { Kato-Katz }\end{array}$ & $\begin{array}{c}\text { No eggs by } \\
\text { Kato-Katz }\end{array}$ & $0 / 96$ & $5 / 51$ & $3 / 52$ & $8 / 199$ & $\begin{array}{l}4 \cdot 0 \\
(1 \cdot 8-7 \cdot 8)\end{array}$ & $\begin{array}{c}\text { No eggs by } \\
\text { Kato-Katz }\end{array}$ & $\begin{array}{c}\text { No eggs by } \\
\text { Kato-Katz }\end{array}$ \\
\hline & 2007 & $2 / 107$ & $1 / 33$ & $0 / 24$ & $3 / 164$ & $\begin{array}{l}1 \cdot 8 \\
(0 \cdot 4-5 \cdot 3)\end{array}$ & $\begin{array}{c}\text { No eggs by } \\
\text { Kato-Katz }\end{array}$ & $\begin{array}{c}\text { No eggs by } \\
\text { Kato-Katz }\end{array}$ & $2 / 51$ & $6 / 59$ & $1 / 34$ & $9 / 144$ & $\begin{array}{l}6 \cdot 3 \\
(2 \cdot 9-11 \cdot 5)\end{array}$ & $\begin{array}{l}2 \cdot 7 \\
(3 \cdot 7)\end{array}$ & $\begin{array}{l}4 \cdot 8 \\
(0-88)\end{array}$ \\
\hline \multirow[t]{2}{*}{ Cattle } & 2006 & $42 / 100$ & $4 / 19$ & $27 / 38$ & $73 / 157$ & $\begin{array}{l}46 \cdot 5 \\
(38 \cdot 5-54 \cdot 6)\end{array}$ & $\begin{array}{l}2 \cdot 3 \\
(2 \cdot 9)\end{array}$ & $\begin{array}{l}1 \cdot 9 \\
(0 \cdot 3-9 \cdot 8)\end{array}$ & $0 / 1$ & $0 / 7$ & - & $0 / 8$ & $\begin{array}{l}0 \\
(0-31 \cdot 2)\end{array}$ & & \\
\hline & 2007 & - & - & - & & & - & & $0 / 1$ & $0 / 6$ & - & $0 / 7$ & $0(0-34 \cdot 8)$ & & \\
\hline Buffalo & 2006 & $3 / 25$ & $0 / 6$ & $1 / 7$ & $4 / 38$ & $\begin{array}{l}10 \cdot 5 \\
(3 \cdot 0-24 \cdot 8)\end{array}$ & $3 \cdot 4$ & $3 \cdot 4$ & & & & & & & \\
\hline \multirow[t]{2}{*}{ Pigs } & 2006 & $0 / 7$ & - & $0 / 12$ & $0 / 19$ & 0 & & & - & $0 / 23$ & $0 / 19$ & $0 / 42$ & $\begin{array}{l}0 \\
(0-6 \cdot 9)\end{array}$ & & \\
\hline & 2007 & $2 / 25$ & $0 / 1$ & $0 / 26$ & $2 / 52$ & $\begin{array}{l}3 \cdot 9 \\
(0 \cdot 4-13 \cdot 2)\end{array}$ & $\begin{array}{l}7 \cdot 0 \\
(9 \cdot 2)\end{array}$ & $\begin{array}{l}2 \cdot 6 \\
(0 \cdot 5-13 \cdot 5)\end{array}$ & - & $0 / 20$ & - & $0 / 20$ & $0(0-13 \cdot 9)$ & & \\
\hline Goats & 2006 & - & - & $11 / 20$ & $11 / 20$ & $\begin{array}{l}55 \\
(31 \cdot 5-77 \cdot 0)\end{array}$ & - & - & - & - & - & & & & \\
\hline \multirow[t]{2}{*}{ Dogs } & 2006 & $2 / 8$ & $0 / 10$ & $0 / 24$ & $2 / 42$ & $\begin{array}{l}4 \cdot 8 \\
(0 \cdot 5-16 \cdot 2)\end{array}$ & - & - & $9 / 34$ & $1 / 23$ & $4 / 17$ & $14 / 74$ & $\begin{array}{l}18 \cdot 9 \\
(10 \cdot 7-29 \cdot 7)\end{array}$ & $\begin{array}{l}1 \cdot 7 \\
(1 \cdot 2)\end{array}$ & $\begin{array}{l}1 \cdot 3 \\
(0 \cdot 4-2 \cdot 8)\end{array}$ \\
\hline & 2007 & $4 / 25$ & $0 / 29$ & $3 / 29$ & $7 / 83$ & $\begin{array}{l}8 \cdot 4 \\
(3 \cdot 5-16 \cdot 6)\end{array}$ & $\begin{array}{l}36 \cdot 9 \\
(86 \cdot 8)\end{array}$ & $\begin{array}{l}3 \cdot 1 \\
(0 \cdot 6-214 \cdot 0)\end{array}$ & $7 / 27$ & $5 / 21$ & $3 / 23$ & $15 / 71$ & $\begin{array}{l}21 \cdot 1 \\
(12 \cdot 3-32 \cdot 4)\end{array}$ & $\begin{array}{l}2 \cdot 3 \\
(4 \cdot 3)\end{array}$ & $\begin{array}{l}0 \cdot 7 \\
(0 \cdot 1-16 \cdot 6)\end{array}$ \\
\hline \multirow[t]{2}{*}{ Cats } & 2006 & $0 / 1$ & - & $0 / 1$ & $0 / 2$ & $\begin{array}{l}0 \\
(0-77 \cdot 6)\end{array}$ & & & $1 / 5$ & $0 / 17$ & $0 / 17$ & $1 / 39$ & $\begin{array}{l}2 \cdot 6 \\
(0 \cdot 1-13 \cdot 5)\end{array}$ & - & - \\
\hline & 2007 & $3 / 6$ & $0 / 2$ & - & $3 / 8$ & $\begin{array}{l}37 \cdot 50 \\
(8 \cdot 4-75 \cdot 6)\end{array}$ & $\begin{array}{l}11 \cdot 1 \\
(14 \cdot 2)\end{array}$ & $\begin{array}{l}3 \cdot 9 \\
(0 \cdot 4-27 \cdot 2)\end{array}$ & $0 / 1$ & $1 / 3$ & $0 / 15$ & $1 / 19$ & $5 \cdot 3(0 \cdot 1-26 \cdot 0)$ & $0 \cdot 2$ & $0 \cdot 2$ \\
\hline \multirow[t]{2}{*}{ Rodents } & 2006 & $0 / 7$ & $0 / 1$ & $0 / 1$ & $0 / 9$ & $\begin{array}{l}0 \\
(0-28 \cdot 3)\end{array}$ & & & $6 / 18$ & $5 / 22$ & $2 / 9$ & $13 / 49$ & $\begin{array}{l}26 \cdot 5 \\
(14 \cdot 9-41 \cdot 1)\end{array}$ & $\begin{array}{l}784 \cdot 5 \\
(1415 \cdot 9)\end{array}$ & $\begin{array}{l}230 \cdot 7 \\
(40 \cdot 3-3311 \cdot 7)\end{array}$ \\
\hline & 2007 & $0 / 3$ & - & - & $0 / 3$ & $\begin{array}{l}0 \\
(0-63 \cdot 2)\end{array}$ & & & $4 / 12$ & $3 / 22$ & $2 / 17$ & $9 / 51$ & $\begin{array}{l}17 \cdot 7 \\
(6 \cdot 4-35 \cdot 1)\end{array}$ & $\begin{array}{l}489 \cdot 1 \\
(1074 \cdot 9)\end{array}$ & $\begin{array}{l}51 \cdot 9 \\
(4 \cdot 8-3268 \cdot 3)\end{array}$ \\
\hline
\end{tabular}

a Infection intensity (EPG) is based on infected host individuals only.

b Only the individuals positive with IHA test received stool examination, therefore prevalence in humans is estimated among seropositive individuals.

GH, HP and XZ refer to Guanghui, Heping and Xingzhuang respectively; LQ, LS and YT refer to Longquan, Longshang and Yuantou, respectively. 
$11 \cdot 8 \%$ and $30.0 \%$ by village, but no infected rodents were found in the marshland. In contrast, within the marshland villages, very high infection prevalence levels were observed within cattle in 2006, ranging from $21 \cdot 05 \%$ to $71 \cdot 05 \%$ by village, but no infected cattle were identified within the hilly region. It was also noted that infected dogs were identified in each hilly village across both years. Infections in human populations, that were positive in the previous IHA test here, were identified in all 6 villages during 2006-2007, with a non-significant increase between the two years in the marshland $\left(\mathrm{X}^{2}=1 \cdot 87, \mathrm{D} . \mathrm{F} .=1\right.$, $P=0 \cdot 17)$ and in the hilly region $\left(\mathrm{X}^{2}=0 \cdot 47, \mathrm{D} . \mathrm{F} .=1\right.$, $P=0 \cdot 49$ ) (see Table 4).

Using the Kato-Katz test, no eggs were found among the majority of the infected humans previously identified through egg hatching, with the exception in the hilly region in 2007 , and, as a result, the intensity in humans should be very low (Zheng et al. 1995). Highest infection intensities in the hilly region were observed in rodents, across both years, while in the marshland there appeared to be no distinct difference in such indices among infected host species (cattle, water buffalo, dogs, cats and pigs; $\mathrm{X}^{2}=0 \cdot 79$, D.F. $\left.=4, P=0.94\right)($ see Table 4$)$.

\section{Contamination index for host species}

Given the mean daily discharged faeces per host for each species (Wang et al. 2005) and an estimate of $1.5 \mathrm{~g}$ of faeces produced by a rodent per day (Ebihara et al. 1998), the number of daily discharged eggs per infected host in the marshland was, $13724 \cdot 1$ for cattle and $49867 \cdot 8$ for water buffalo in 2006, and 10612 for pigs, $3653 \cdot 1$ for dogs and 222 for cats in 2007 . The index in the hilly region was $168 \cdot 3$ for dogs and $1176 \cdot 8$ for rodents in 2006, and 432 for humans, $227 \cdot 7$ for dogs, 733.7 for rodents and 4 for cats in 2007. Therefore, the contamination index (the total number of discharged eggs per day) in the marshland was, in descending order, $2220681 \cdot 8$ eggs from cattle and 314954.5 from water buffalo in 2006, and $37958 \cdot 3$ from pigs, $31117 \cdot 4$ from dogs and $1831 \cdot 5$ from cats in 2007; whereas such index in the hilly region was, with the exception of rodents, 2833.8 from dogs in 2006, and $5291 \cdot 6$ from dogs, $4050 \cdot 0$ from humans, and 20 from cats in 2007.

\section{DISCUSSION}

The present study demonstrated that, based on the infection prevalence and intensity in each species, combined with the estimated total number of daily discharged eggs (or per infected host), small rodents, with an ability of rapid reproduction, and potentially more opportunities to come into contact with water sources and then defecate on snail inhabited ditches, may play an important role in the transmission of $S$. japonicum in the hilly regions. In contrast, within the marshland regions, bovines (and to some extent, goats based on infection prevalence only) appear primarily responsible for ongoing transmission. Furthermore, a relatively high infection prevalence was discovered in dogs (and cats) in both geographical regions, together with a relatively high transmission index (eggs per day) estimate, raising potentially important implications for current control criteria of $S$. japonicum in China (Liang et al. 2006), which is essentially based on infection in humans and bovines, rather than any current concern over other less agriculturally important domestic animals.

Small rodents have long been considered of little or no importance in $S$. japonicum transmission in China (Minggang and Zheng, 1999) due mainly to the much lower amount of discharges from rodents compared to that from humans or bovines. Another important reason is that recent research has either generally documented a very low prevalence $(0 \cdot 3-3 \cdot 0 \%)$ of $S$. japonicum in small rodents (Yang et al. 2000; Zheng, 2006), or involved no attempts to collect faecal samples from such animals (Li et al. 2005 ; Wang et al. 2005 ; Zhao et al. 2005 ; Balen et al. 2007), which is potentially due to the logistical difficulty inherent in the sampling of wild rodents (Webster and Macdonald, 1995). It may not be surprising that no quantitative estimation of the role of such species in the transmission of $S$. japonicum in China has (to the authors' knowledge) been made, as the necessary parasitological survey data have generally not been available.

In contrast, bovines (water buffalo and domestic cattle) have been considered one of the most important contributors to $S$. japonicum transmission within the lake/marshland areas of China due to their large herds, free-roaming behaviour, life span and potentially high number of eggs passed with their faeces (Ross et al. 2001; Guo et al. 2006; Gray et al. 2007). Schistosomiasis control in bovines has therefore long been regarded as a major part of the Chinese national schistosomiasis control programme (Anonymous, 1990). Indeed, in this study, we also found that the highest infection (and the highest eggs per day contamination index) was in bovines in 2006, and also goats, which is consistent with previous reports from within one marshy village within Anhui (Wang et al. 2005 ; Zhao et al. 2005). However, within the hilly region no infected bovines were found. This difference may be explicable by 2 factors: one is that very few bovines were raised in local hilly villages and the other may be attributed to a specific pattern of rearing bovines there. In the hilly region, bovines graze on the slopes of the hills, and therefore have little or no contact with snail habitats (which are largely concentrated in irrigation ditches), unlike bovines in the marshland region which graze on snail-inhabited pastures. Generally bovines are suspected to be less important within hilly regions 
relative to that of the marshland or lowland areas, as has been discussed by Shrivastava and colleagues (Shrivastava et al. 2005) and Seto and colleagues (Seto et al. 2002), although the latter supposed that transmission may still be maintained in these areas indirectly through agricultural fertilization practices which involve usage of untreated human and animal excrement. However, this was not the case in the hilly region of the current study, as bio-gas toilets, using faeces from humas or agriculturally important domestic animals as material to produce bio-gas, during which most pathogens are killed under anaerobic conditions inside the digester (Jha, 2003), are relative common. The coverage of the toilets, for example, is $39 \%$ in Longquan village and $48 \%$ in Yuantou village, thus reducing the opportunities for faecal contamination of the water sources.

The role of infected humans in the maintenance or re-emergence of $S$. japonicum transmission, through migration into new regions, application of fresh faeces as fertilizer or occasionally through 'night soil' due to personal behaviours, has been demonstrated (Zheng et al. 1991; Cheng et al. 1994). However, in both Shitai County and Tongling County, the role of humans appears to be of less importance in transmission. The infection prevalence in humans, despite being overestimated here (since it was estimated among sero-positive individuals rather than among the total population), at $0 \cdot 4-1 \cdot 8 \%$ in the marshland and $4 \cdot 0-6 \cdot 3 \%$ in the hilly villages, was still very low compared to that in bovines or rodents, and the infection intensity was nearly negligible. Furthermore, great improvement in sanitation was noted to have occurred in the sampled villages as mentioned above, which, along with annual control measures such as health education and selective treatment, would further reduce the chances of humans contaminating snail habitats (Guo et al. 2005).

Infection in dogs (and cats) has infrequently or rarely been reported in China for over 10 years due primarily to logistical difficulties in sampling faeces from these species, as indeed was encountered in the current study. Dogs (and cats) are free roaming and, dogs in particular, usually follow their owners when they engage in agricultural production, for example, herding bovines, cutting grass and/or planting crops in areas near snail habitats. Moreover, if such animals drink from small ponds or ditches during these periods, this could not only enhance their water contact with snail habitats but also possibly lead to their frequent defaecation at such locations. In this study, the high infection prevalence and intensity levels observed among dogs, coupled with their high mobility and consequent defecation activities, might indicate a significant role of these animals in the transmission and/or dispersal of S. japonicum in the endemic communities within two regions. Indeed, there is increasing evidence to suggest that dogs may play an important role in S. japonicum transmission in the Philippines (McGarvey et al. 2006; Rudge et al. 2008). However, from parasitological data alone here it is unclear whether transmission could be maintained within dogs in the absence of bovines in the marshland or of rodents in the hilly regions, or whether they are mainly just 'spill-over' hosts. This is one question we are currently exploring using mathematical models fitted to these data. Pigs are also potentially important hosts (Johansen et al. 2000), although they are relatively short-lived and often restricted to pens to fatten faster and/or provide faeces for biogas production, both in the marshland and in the hilly region. After examination of 133 pigs, however, we found 2 infected pigs in 1 marshland village which were not fenced, despite the fact that the local government has forbidden bovines, goats or sheep, rather than pigs, to live in the marshland since January of 2007. This may thereby highlight the need for continued vigilance across all potential definitive host species for successful disease control.

The different trend in changes of infection prevalence in snails and infected snail density between the two regions could partly reflect the effects of contrasting reservoirs or different control measures (and/or frequencies or coverage) between regions. Indeed, although intensive mollusciciding had been conducted annually in the hilly region, 2 hilly villages showed an increase in snail indices, indicating the possible existence of other important reservoirs apart from humans. The decrease in snail measures in April 2007 in the marshland may not be easily accredited to the replacement of bovines (and goats) implemented in January of 2007, as most contamination of snail habitats by these animals would likely have already occurred during the previous year (Liang et al. 2005). Since snail measures are variable across seasons (Davis et al. 2006), more caution should be given when interpreting the implication of such snail indices.

It should, however, be mentioned that there are several inherent limitations within the current study. First, the dilemma in the detection of infection in humans and animals still remains. The Kato-Katz test, one standard method for the detection and quantification of egg burdens in humans (Katz et al. 1972), has poor sensitivity, especially when infection intensity is very low (Yu et al. 2007), and also cannot be conducted on faeces from animals with a high content of fibrous material (Guo et al. 2001). Here we could not detect any eggs in some infected humans, who here were identified through the previous hatching test. The hatching test indeed improves test sensitivity, but the required time, natural water, temperature and the disposal of large amount of waste limit its application in field surveys. Therefore, prevalence surveys using the hatching test were limited to the examination of samples from a single time point without considering day-to-day variation of egg excretion in stool (Carabin et al. 2005) and, 
also due to time limitations of field work, infection intensity was not measured for each infected animal. Second, differences in the amount of faeces examined or in the sampling procedures, for example from cats, among species might be slightly problematic when directly comparing infection prevalence and intensity between species. Due to the logistic difficulty in the sampling of dogs, cats and small rodents, we were not able to get the required amount of faeces each time, as proposed by Wang et al. (2005), and thus each sample as a whole, after being weighed, was examined with the miracidia hatching and eggs from the miracidia-positive sediments after hatching were count.

Schistosomiasis is of great importance in terms of public health in China with the majority (80\%) of cases occurring around the lake (Dongting and Poyang) and marshland regions of 5 provinces in southern China - Hunan, Jiangxi, Anhui, Hubei and Jiangsu (Zhou et al. 2005), and a recent village-based intervention trial (human and bovine praziquantel treatment versus human praziquantel treatment only) has confirmed that bovines are the major reservoir host of human schistosomiasis in the lake and marshland regions (Gray et al. 2009). However, the contribution of different species of hosts to the transmission of $S$. japonicum may vary with regions in China, particularly between mountainous/hilly regions (Zheng et al. 1997) and marshland/lake regions (Gray et al. 2007, 2009). Indeed, the present study here demonstrates contrasting infection profiles of $S$. japonicum in mammals between the two piloted regions, and suggests that in the previously controlled hilly areas, rodents may be the most important reservoir for $S$. japonicum, whereas in the marshland, bovines may have been playing a major part in the transmission of the disease. The role of dogs (and cats) should not be ignored in both regions, and human infection seems inevitable in such areas. More evidence may be needed to further elucidate the role of rodents as the main reservoirs in the hilly regions. Nevertheless, the practical and primary implications from the current results are that, in the hilly areas, human- or bovine-based control strategies alone may not be sufficient for controlling transmission and therefore more efforts should perhaps focus on intermediate host snail control and environmental management, in order to minimize the snail density and infected snail habitats. Moreover, chemotherapy of dogs (and cats) might also help reduce the degree to which the disease is transmitted if dogs (and cats) play a role in the transmission.

\section{ACKNOWLEDGEMENTS}

We are very grateful to Mr Ai-Yan Shen and his team from Shitai County Centre for Disease Control, and Mr XingPing Pan and his team from Tongling Schistosomiasis Control Station for help with the infection prevalence survey in mammals and snails in field. Many thanks go to
Wei-Duo Wu, Feng-Feng Wang, Lei Zhu, Luo-Sheng Zhuang, Zhi-Guo Cao, and Da-Ling Chen from Anhui Institute of Parasitic Diseases for their help and support in field surveys and Dr Manoj Gambhir for his careful reading and critical comments of the manusript.

F UNDING

This work was funded by The Royal Society (Grant no. P07445 to J.P.W.), The Kwok Foundation (to D.B.L., C.A.D. and J.P.W.), and the Medical Research Council (to J.W.R.).

\section{CONFLICTS OF INTEREST}

The authors have declared that no competing interests exist.

\section{AUTHOR CONTRIBUTIONS}

J.P.W., D. B.L. and T.P.W. conceived and designed the study. D.B.L. collected baseline data. T.P.W. provided logistical support for all the fieldwork. D. B. L. and G. R. F. took part in snail surveys in field. D.B.L., G.R.F. and J.W.R. took part in prevalence survey of $S$. japonicum in definitive hosts. D.B.L., J.P.W., C.A.D., and J.W.R. wrote the paper.

\section{REFERENCES}

Anonymous (1990). Manual of Schistosomiasis Control. Bureau of Endemic Disease Control, Ministry of Health. House of Shanghai Science Technique, Shanghai, China.

Balen, J., Zhao, Z. Y., Williams, G. M., McManus, D. P., Raso, G., Utzinger, J., Zhou, J. and Li, Y. S. (2007). Prevalence, intensity and associated morbidity of Schistosoma japonicum infection in the Dongting Lake region, China. Bulletin of the World Health Organization 85, 519-526.

Calhoun, J. B. (1962). The Ecology and Sociology of the Norway Rat. U.S. Dept. Health, Education and Welfare, Public Health Service, Bethesda, MD, USA.

Cao, S. Q. and Wu, M. Y. (2004). An investigation of our break of acute schistosomiasis in Shitai county of Anhui. Tropical Diseases and Parasitology 1, 67-68.

Carabin, H., Balolong, E., Joseph, L., McGarvey, S. T., Johansen, M. V., Fernandez, T., Willingham, A. L. and Olveda, R. (2005). Estimating sensitivity and specificity of a faecal examination method for Schistosoma japonicum infection in cats, dogs, water buffaloes, pigs, and rats in Western Samar and Sorsogon Provinces, The Philippines. International Fournal for Parasitology 35, 1517-1524. doi : 10.1016/ j.ijpara.2005.06.010.

Chen, G. X., Wang, M. S., Han, S. M., Ou, N. and He, Z. G. (2004). Observation on the effect of the comprehensive measures of replacing cattle with machine and reconstructing water supply and lavatory to control the transmission of schistosomiasis. Tropical Diseases and Parasitology 4, 342-345.

Chen, M. G. (2005). Use of praziquantel for clinical treatment and morbidity control of schistosomiasis 
japonica in China: a review of 30 years' experience. Acta Tropica 96, 168-176.

Cheng, D. J. and Gong, Z. G. (1989). An epidemiological investigation of schistosomiasis in Liantieshan region. Chinese Fournal of Schistosomiasis Control 1, 10.

Cheng, P. J., Yong, S. M., Huang, Y. Y. and Liu, J. S. (1994). An investigation and management of the re-emerging schistosomiasis in one village.

Chinese Fournal of Schistosomiasis Control 6, 112-113.

Davis, G. M., Wu, W. P., Williams, G., Liu, H. Y., Lu, S. B., Chen, H. G., Zheng, F., McManus, D. P. and Guo, J. G. (2006). Schistosomiasis japonica intervention study on Poyang Lake, China: the snail's tale. Malacologia 49, 79-105.

Ebihara, K., Shiraishi, R. \& Okuma, K. (1998). Hydroxypropyl-modified potato starch increases fecal bile acid excretion in rats. The Fournal of Nutrition 128, 848-854.

Fedorko, J. M. (1999). Schistosoma japonicum in the black rat, Rattus rattus mindanensis, from Leyte, Philippines in relation to Oncomelania snail colonies with reference to other endoparasites. The Southeast Asian Fournal of Tropical Medicine and Public Health 30, 343-349.

Feldmeier, H. and Poggensee, G. (1993). Diagnostic techniques in schistosomiasis control. A review. Acta Tropica 52, 205-220.

Gray, D. J., Williams, G. M., Li, Y., Chen, H., Li, R. S., Forsyth, S. J., Barnett, A. G., Guo, J., Feng, Z. and McManus, D. P. (2007). A cluster-randomized bovine intervention trial against Schistosoma japonicum in the People's Republic of China: design and baseline results. American Fournal of Tropical Medicine and Hygiene 77, 866-874.

Gray, D. J., Williams, G. M., Li, Y., Chen, H., Forsyth, S. J., Li, R. S., Barnett, A. G., Guo, J., Ross, A. G., Feng, Z. and McManus, D. P. (2009). A cluster-randomised intervention trial against Schistosoma japonicum in the Peoples' Republic of China: bovine and human transmission. PLoS ONE 4, e5900. doi:10.1371/journal.pone.0005900.

Gui, M., Idris, M. A., Shi, Y. E., Muhling, A. and Ruppel, A. (1991). Reactivity of Schistosoma japonicum and $S$. mansoni antigen preparations in indirect haemagglutination (IHA) with sera of patients with homologous and heterologous schistosomiasis. Annals of Tropical Medicine and Parasitology 85, 599-604.

Guo, J. G., Cao, C. L., Hu, G. H., Lin, H., Li, D., Zhu, R. and Xu, J. (2005). The role of 'passive chemotherapy' plus health education for schistosomiasis control in China during maintenance and consolidation phase. Acta Tropica 96, 177-183. doi:10.1016/ j.actatropica.2005.07.012.

Guo, J., Li, Y., Gray, D., Ning, A., Hu, G., Chen, H., Davis, G. M., Sleigh, A. C., Feng, Z., McManus, D. P. and Williams, G. M. (2006). A drug-based intervention study on the importance of buffaloes for human Schistosoma japonicum infection around Poyang Lake, People's Republic of China. American Fournal of Tropical Medicine and Hygiene 74, 335-341.

Guo, J. G., Ross, A. G., Lin, D. D., Williams, G. M., Chen, H. G., Li, Y., Davis, G. M., Feng, Z., McManus, D. P. and Sleigh, A. C. (2001). A baseline study on the importance of bovines for human
Schistosoma japonicum infection around Poyang Lake, China. American Fournal of Tropical Medicine and Hygiene 65, 272-278.

He, Y., Luo, X., Zhang, X., Yu, X., Lin, J., Li, Y., Li, Y. and Liu, S. (1999a). Immunological characteristics of natural resistance in Microtus fortis to infection with Schistosoma japonicum. Chinese Medicine Fournal (Engl) 112, 649-654.

He, Y. K., Li, Y., Liu, S. X., Luo, X. S., Yu, X. L., Lin, J. L., Zhang, X. Y., Yu, D. B. and McManus, D. P. (1999b). Natural antibodies in Microtus fortis react with antigens derived from four stages in the life-cycle of Schistosoma japonicum. Annals of Tropical Medicine and Parasitology 93, 83-87.

Ho, Y. H. (1963). On the host specificity of Schistosoma japonicum. Chinese Medicine Fournal 82, 405-414.

Jha, P. K. (2003). Health and social benefits from improving community hygiene and sanitation: an Indian experience. International Fournal of Environmental Health Research 13 (Suppl), S133-S140. doi:10.1080/0960312031000102895.

Johansen, M. V., Bogh, H. O., Nansen, P. and Christensen, N. O. (2000). Schistosoma japonicum infection in the pig as a model for human schistosomiasis japonica. Acta Tropica 76, 85-99.

Katz, N., Chaves, A. and Pellegrino, J. (1972). A simple device for quantitative stool thick-smear technique in Schistosomiasis mansoni. Revista do Instituto de Medicina Tropical de São Paulo 14, 397-400.

Li, Y. S., Zhao, Z. Y., Ellis, M. and McManus, D. P. (2005). Applications and outcomes of periodic epidemiological surveys for schistosomiasis and related economic evaluation in the People's Republic of China. Acta Tropica 96, 266-275. doi:10.1016/ j.actatropica.2005.07.020.

Liang, S., Spear, R. C., Seto, E., Hubbard, A. and Qiu, D. (2005). A multi-group model of Schistosoma japonicum transmission dynamics and control: Model calibration and control prediction. Tropical Medicine छे International Health 10, 263-278. doi:10.1111/ j.1365-3156.2005.01386.x.

Liang, S., Yang, C., Zhong, B. and Qiu, D. (2006). Re-emerging schistosomiasis in hilly and mountainous areas of Sichuan, China. Bulletin of the World Health Organization 84, 139-144. doi:/S004296862006000200015.

Mao, S. P. (1990). Schistosome Biology and Control of Schistosomiasis. Publishing House for People's Health, Beijing, China.

McGarvey, S. T., Carabin, H., Balolong, E., Jr., Belisle, P., Fernandez, T., Joseph, L., Tallo, V., Gonzales, R., Tarafder, M. R., Alday, P., Willingham, A. L. and Olveda, R. (2006). Cross-sectional associations between intensity of animal and human infection with Schistosoma japonicum in Western Samar province, Philippines. Bulletin of the World Health Organization 84, 446-452. doi:S004296862006000600013.

McManus, D. P. and Bartley, P. B. (2004). A vaccine against Asian schistosomiasis. Parasitology International 53, 163-173. doi:10.1016/ j.parint. 2004.01 .006 . 
Meehan, A. P. (1984). Rats and mice: their biology and control. Rentokil Limited, Tonbridge, Kent, UK.

Minggang, C. and Zheng, F. (1999). Schistosomiasis control in China. Parasitology International 48, 11-19.

Mitchell, G. F., Garcia, E. G., Wood, S. M., Diasanta, R., Almonte, R., Calica, E., Davern, K. M. and Tiu, W. U. (1990). Studies on the sex ratio of worms in schistosome infections. Parasitology 101, 27-34.

Ross, A. G., Sleigh, A. C., Li, Y., Davis, G. M., Williams, G. M., Jiang, Z., Feng, Z. and McManus, D. P. (2001). Schistosomiasis in the People's Republic of China: prospects and challenges for the 21st century. Clinical Microbiology Reviews 14, 270-295. doi:10.1128/CMR.14.2.270295.2001.

Rudge, J. W., Carabin, H., Balolong, E., Tallo, V., Shrivastava, J., Lu, D. B., Basanez, M. G., Olveda, R., McGarvey, S. T. and Webster, J. P. (2008). Population genetics of Schistosoma japonicum within the Philippines suggest high levels of transmission between humans and dogs. PLoS Neglected Tropical Diseases 2, e340. doi:10.1371/journal.pntd.0000340.

Seto, E., Xu, B. and Liang, S. (2002). The use of remote sensing for predictive modelling of schistosomiasis in China. American Society for Photogrammetry and Remote Sensing 68, 167-174.

Shrivastava, J., Barker, G. C., Johansen, M. V., Zhou, X. N. and Aligui, G. D. (2003). Isolation and characterization of polymorphic DNA microsatellite markers from Schistosoma japonicum. Molecular Ecology Notes 3, 406-408.

Shrivastava, J., Qian, B. Z., McVean, G. and Webster, J. P. (2005). An insight into the genetic variation of Schistosoma japonicum in mainland China using DNA microsatellite markers. Molecular Ecology 14, 839-849. doi:10.1111/j.1365294X.2005.02443.x.

Wang, L. D., Chen, H. G., Guo, J. G., Zeng, X. J., Hong, X. L., Xiong, J. J., Wu, X. H., Wang, X. H., Wang, L. Y., Xia, G., Hao, Y., Chin, D. P., and Zhou, X. N. (2009). A strategy to control transmission of Schistosoma japonicum in China. New England Fournal of Medicine 360, 121-128. doi:10.1056/ NEJMoa0800135.

Wang, T. P., Shrivastava, J., Johansen, M. V., Zhang, S. Q., Wang, F. F. and Webster, J. P. (2006b). Does multiple hosts mean multiple parasites? Population genetic structure of Schistosoma japonicum between definitive host species. International Fournal for Parasitology 36, 1317-1325.

Wang, T. P., Vang Johansen, M., Zhang, S. Q., Wang, F. F., Wu, W. D., Zhang, G. H., Pan, X. P., Ju, Y. and Ornbjerg, N. (2005). Transmission of Schistosoma japonicum by humans and domestic animals in the Yangtze River valley, Anhui Province, China. Acta Tropica 96, 198-204. doi:10.1016/ j.actatropica.2005.07.017.

Wang, X. H., Wu, X. H. and Zhou, X. N. (2006a). Bayesian estimation of community prevalences of Schistosoma japonicum infection in China. International Fournal for Parasitology 36, 895-902. doi:10.1016/j.ijpara.2006.04.003. doi:10.1016/ j.ijpara.2006.06.011.

Webster, J. P. and Macdonald, D. W. (1995). Survey of the parasites and pathogens carried by wild brown rats, Rattus norvegicus, on UK farmsteads. Parasitology 111, 247-255.

Wu, K. (1957). Schistosomiasis japonica among domestic and wild animals in China. Chinese Fournal of Veterinary 3, 98-100.

Wu, Z. D., Lu, Z. Y. and Yu, X. B. (2005). Development of a vaccine against Schistosoma japonicum in China: a review. Acta Tropica 96, 106-116. doi:10.1016/ j.actatropica.2005.08.005.

Xu, G. Y., Tian, J. C., Cheng, G. M., Yang, H. M., Qiu, L., Hu, H. B., Xie, Z. Y., Zhou, F. and Ying, W. G. (1999). Observation on natural focal disease of schistosomiasis in Rattus norvegicus in Nanjing. Chinese Fournal of Parasitic Diseases 7, 4-6.

Yang, G. R., Wu, X., Xiong, M. T., Fan, C., Wu, H. and Tao, K. (2000). Investigation on Schistosoma japonicum infection in rodents in Yunnan Province. Chinese Yournal of Parasitology \& Parasitic Diseases 18, 232-235.

Yao, B. Y., Zheng, J. and Qian, K. (1989). An epidemiological investigation of $S$. japonicum in animals in mountainous areas. Chinese Fournal of Schistosomiasis Control 1, 1-3.

Yu, J. M., de Vlas, S. J., Jiang, Q. W. and Gryseels, B. (2007). Comparison of the Kato-Katz technique, hatching test and indirect hemagglutination assay (IHA) for the diagnosis of Schistosoma japonicum infection in China. Parasitology International 56, 45-49. doi:10.1016/j.parint.2006.11.002.

Yuan, Y., Xu, X. J., Dong, H. F., Jiang, M. S. and Zhu, H. G. (2005). Transmission control of schistosomiasis japonica: implementation and evaluation of different snail control interventions. Acta Tropica 96, 191-197. doi:10.1016/ j.actatropica.2005.07.014.

Zhao, G. M., Zhao, Q., Jiang, Q. W., Chen, X. Y., Wang, L. Y. and Yuan, H. C. (2005). Surveillance for schistosomiasis japonica in China from 2000 to 2003. Acta Tropica 96, 288-295. doi:10.1016/ j.actatropica.2005.07.023.

Zheng, J., Bie, S. Z., Gao, H. J., Yang, S. D., Pu, H. Z. and Zhou, Z. B. (1991). The faecal resources of water contamination and the role in transmission of schistosomiasis in mountainous areas. Chinese Fournal of Zoonoses 7, 47-49.

Zheng, J., Wu, X. H. and Li, Y. S. (1995). Kato-Katz stool examinations in schistosomiasis control of China. Chinese Fournal of Schistosomiasis Control 7, 382-384.

Zheng, J., Zheng, Q. S., Wang, X. F. and Hua, Z. H. (1997). Influence of livestock husbandry on schistosomiasis transmission in mountainous regions of Yunnan Province. The Southeast Asian Fournal of Tropical Medicine and Public Health 28, 291-295.

Zheng, J. (2006). The role of animals in Schistosoma japonicum transmission. Chinese Fournal of Zoonoses 16, $87-88$.

Zhou, X. N., Wang, T. P., Wang, L. Y., Guo, J. G., Yu, Q., Xu, J., Wang, R. B., Chen, Z. and 
Jia, T. W. (2004). The current status of schistosomiasis epidemics in China. Chinese Fournal of Epidemiology 25, $555-558$

Zhou, X. N., Wang, L. Y., Chen, M. G., Wu, X. H., Jiang, Q. W., Chen, X. Y., Zheng, J. and Utzinger, J. (2005). The public health significance and control of schistosomiasis in China-then and now. Acta Tropica 96, 97-105. doi:10.1016/ j.actatropica.2005.07.005.

Zhu, Y. C. (2005). Immunodiagnosis and its role in schistosomiasis control in China: a review. Acta Tropica 96, 130-136. doi:10.1016/j.actatropica.2005.07.007. 